\title{
Analyzing Suspended Sediment Concentration in Estuarine and Coastal Water Area Based on Rouse Equation
}

\author{
Zhu Wenjin, Zhao Longwei \\ School of Civil Engineering, Huaihai Institute of Technology, Lianyungang 222006
}

\begin{abstract}
In order to expand the Rouse equation to more widely, statistical methods will be combined with the linear form of Rouse equation. Sediment concentration will be taken as a "random variable", while some parameters are selected as variables. Multiple linear regressions will be used for determining the influence of the variables. Correlation coefficient between calculated and measured sediment concentration show that the variables can be used in response to dynamic conditions in a coastal region-Hai'an Bay.
\end{abstract}

KEYWORD: Rouse equation; multiple linear regressions; Hai'an Bay; suspended sediment

Compared with the issue of river sediment, estuarine and coastal sediment have difference and difficulty in (such conditions) including: unsteady flow, combining current and wave, transport processes more complex. Rouse equation is one of the most extensive methods of the diffusion theory which can be used for determining sediment vertical distribution and sediment settling velocity [1-5].

$$
\frac{c(z)}{c_{a}}=\left[\frac{a(h-z)}{z(h-a)}\right]^{\omega_{s} / \kappa u_{*}}
$$

Where $\mathrm{C}$ is the suspended sediment concentration, $w_{s}$ the settling velocity of the sediment particle, $u_{*}$ the shear velocity, $k$ the Karman's constant, $c_{a}$ "reference concentration at a, distance $z$ from the bottom", $h$ the total flow depth.

However, for the assumptions of the equation, it can only be used in small waves and no densitystratified fluids with no acceleration and deceleration. In order to expand the Rouse equation to more wide level, statistical methods would be combined with the linear form of Rouse equation[68]. Sediment concentration would be taken as a "random variable" (seen in equation[5]. Multiple linear regressions would be used for determining the influence of the variables. Correlation coefficient between the calculated and measured sediment concentration. Sediment concentration had shown that the variables can be used in response to dynamic conditions in a coastal region-Hai'an Bay.

\section{REGIONAL OVERVIEW OF HAI'AN BAY}

Hai'an Bay is located in the northern part of the Qiongzhou Strait.Sediment concentration is approximately $0.1 \mathrm{~kg} / \mathrm{m}^{3}$ in Hai'an Bay.

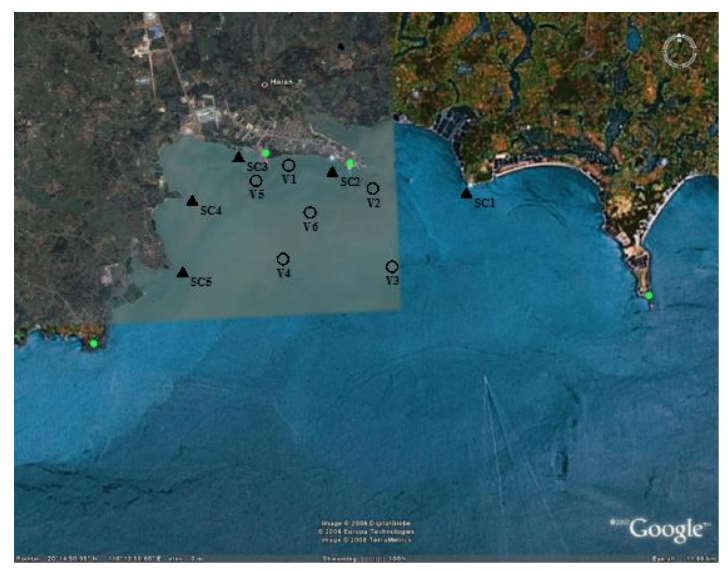

Fig.1 Plan sketch and observation stations of Hai'an Bay

\section{IMPROVEMENTS ROUSE EQUATION}

In order to expand the Rouse equation more widely, statistical methods will be combined with the linear form of Rouse equation. Equation (1) can be changed into:

$$
\ln \frac{c}{c_{a}}=a_{0}+a_{1} \ln \frac{h-z}{z}
$$

Formula (2) can be further rewritten as:

$$
\ln c=a_{0}+a_{1} \ln \frac{h-z}{z}+\ln c_{a}
$$


Where it is assumed that $a_{0}$ and $a_{1}$ are coefficient, which can be got by regression analysis using the field data. It was used regression analysis method for 6 observation stations (Figure 1) vertical sediment concentration data in May 2008 in Qiongzhou Strait Haian Bay. The results are shown in Figure 2.

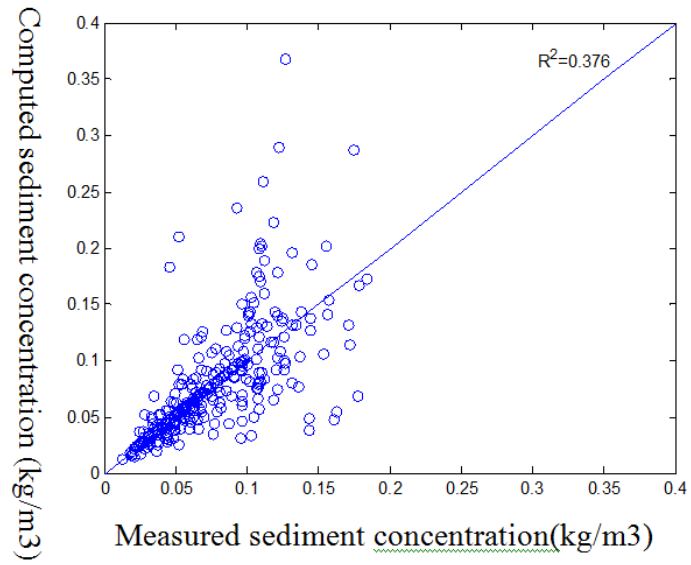

Fig.2 Correlation coefficient between calculated and measured sediment concentration using formula (3)

Through using formula (3) given in equation form, there are more two adjustable coefficients than the original Rouse equation. The calculation results with $R^{2}=0.376$ had shown that the accuracy improved. However, it is still needed to further improvement of the accuracy.

In order to improve the relationship between sediment concentration at each point and the reference point, it is introduced another unknown parameters. The introduction of $p_{s}$ is dimensionless. Formula (3) could be further rewritten as:

$$
\ln \frac{c}{\rho_{s}}=a_{0}+a_{1} \ln \frac{h-z}{z}+a_{3} \ln \frac{c_{a}}{\rho_{s}}
$$

It was also used regression analysis method with equation (4) for 6 observation stations (Figure 1) vertical sediment concentration data in May 2008 in Qiongzhou Strait Haian Bay. The results are shown in Figure 3.

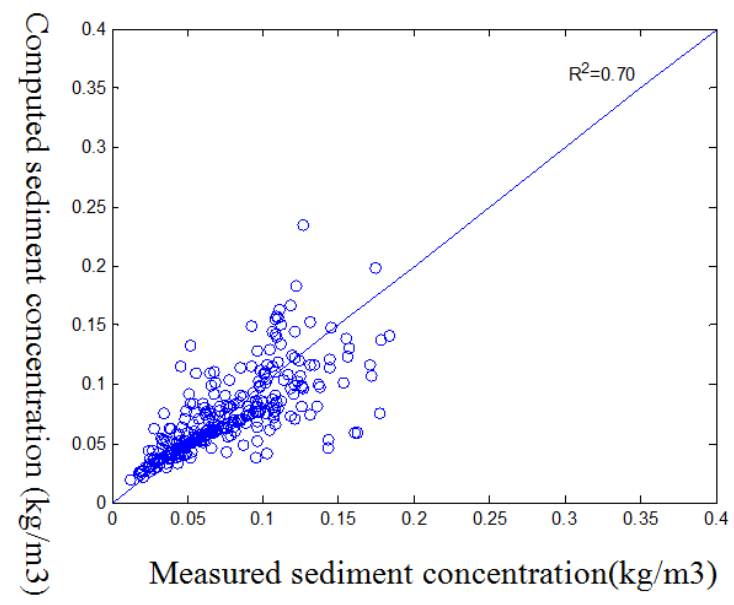

Fig. 3 Correlation coefficient between calculated and measured sediment concentration using formula (4)
It is shown in figure 3 that formula (4) with $R^{2}=0.70$ improve the calculation accuracy greatly. Some scholars had also found sediment concentration flow rate and velocity gradient existing intrinsically relationship by experiment. Hence, based on formula (4) sediment concentration will be taken as a "random variable"(seen in equation(5)).

It is taken surface sediment concentration as reference concentration $c_{a}$, which can be got easily by satellite pictures or water sampling, etc. The finally equation can be rewritten as

$$
\ln \frac{c}{\rho_{s}}=a_{0}+a_{1} \ln \frac{h-z}{z}+a_{3} \ln \frac{c_{a}}{\rho_{s}}+a_{4} \ln \frac{u^{2}}{g d}
$$

It was used regression analysis method with equation (5) for 6 measured stations (Figure 1) vertical sediment concentration data in may 2008 in Qiongzhou Strait Haian Bay. The results are shown in Figure 4. The horizontal coordinate -axis is the sum of measured sediment concentration data, while the other ordinate is computed sediment concentration value.

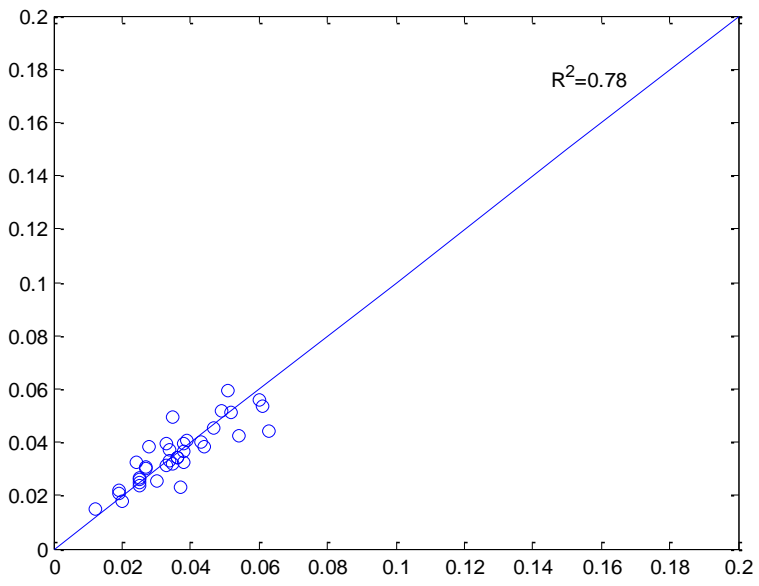

a) V1 Station

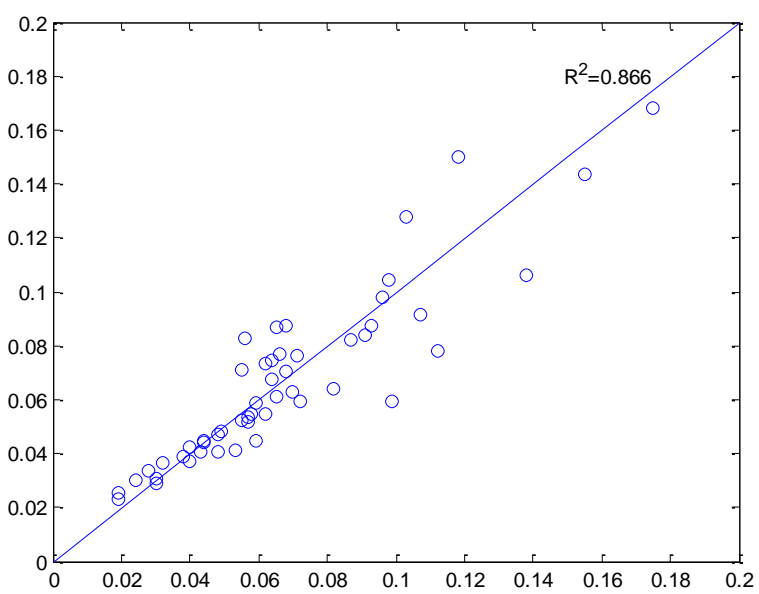

b)V2 Station 


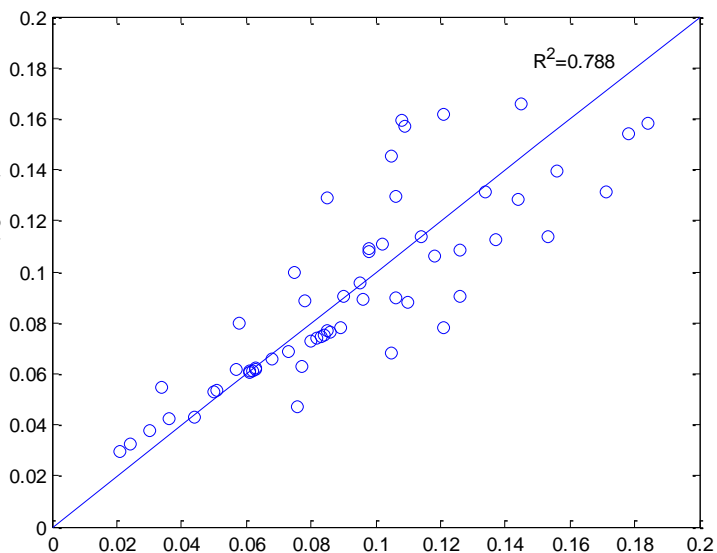

c) V3 Station

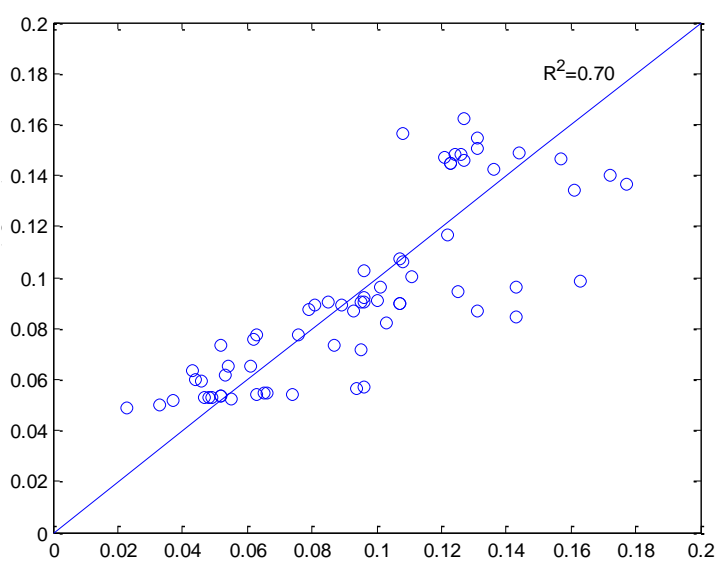

d) V4 Station

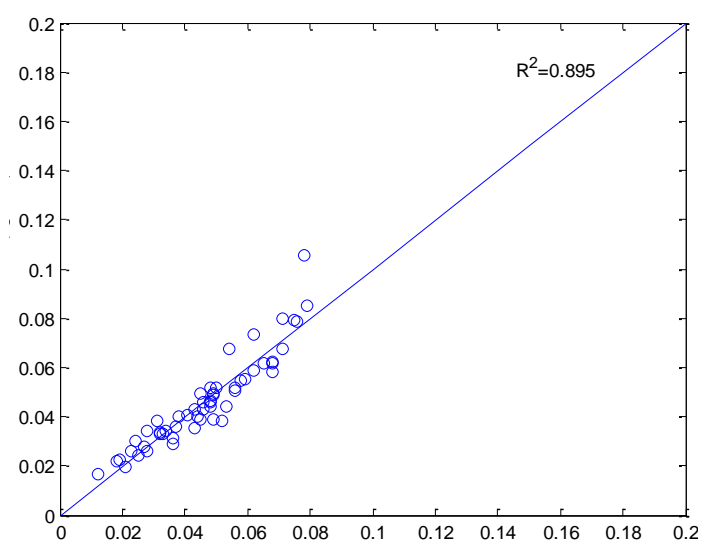

e) V3 Station

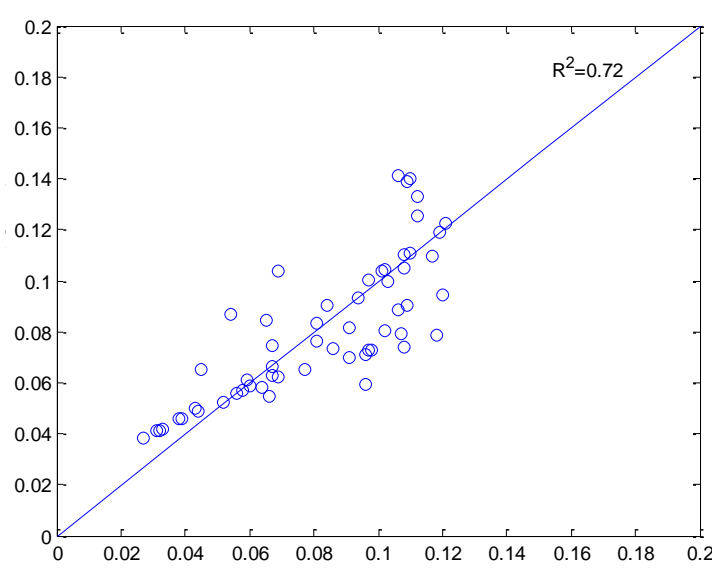

f) V4 Station

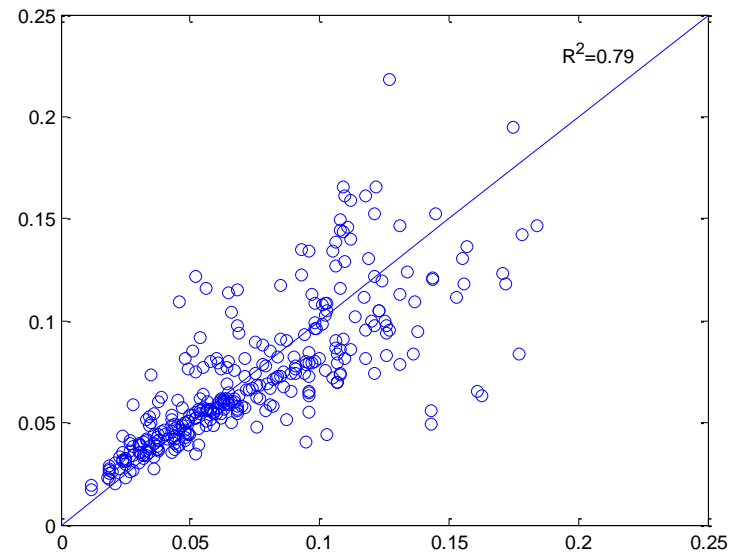

g) all data collocated at 6 measured stations

Fig.4 Correlation coefficient between calculated and measured sediment concentration using formula (5)

The regression coefficients of multiple linear regression equation and other relevant variables are gotten by field data. These values are shown at Tab.1

Tab.1 Regression coefficients and other relevant variables at formula (5)

\begin{tabular}{|c|c|c|c|c|c|}
\hline$a_{0}$ & $a_{1}$ & $a_{2}$ & $a_{3}$ & $R^{2}$ & $\mathrm{~F}$ \\
\hline-3.9711 & 0.585 & 0.095 & 0.049 & 0.790 & 281.990 \\
\hline
\end{tabular}

Multiple linear regressions would be used for determining the influence of the variables. Correlation coefficient between calculated and measured sediment concentration have shown that those variables could be used in response to dynamic conditions in a coastal region-Hai'an Bay.

\section{CONCLUSION}

Rouse equation is one of the most extensive methods of the diffusion theory which can be used for determining sediment vertical distribution and sediment settling velocity. However, for the assumptions of the equation, it can only be used in small wave and no density-stratified with no acceleration and deceleration. In order to expand the Rouse equation to more wide level, statistical methods will be combined with the linear form of Rouse equation. Sediment concentration will be taken as a "random variable"(seen in equation(5)). Multiple linear regressions will be used for determining the influence of the variables. Correlation coefficient between calculated and measured sediment concentration show that the variables can be used in response to dynamic conditions in a coastal region-Hai'an Bay.

\section{ACKNOWLEDGEMENTS}

This work was financially supported by the Natural Science Fund for Colleges and Universities in 
Jiangsu Province (Grant No.13KJB570001), the Natural Science Foundation of Jiangsu Province (Grant No.BK20130409).

\section{REFERENCES}

[1] LI Rui-jie, Yan Yi-xin, SONG Zhi-Yao: Calculation of suspended sediment transport in taiping waterway[J].Journal of Sediment Research,2008(4):5-7.

[2] LI Rui-jie, LUO Feng, ZHU Wen-jin: The suspended sediment transport equation and its near-bed sediment flux. Science in China: Series E, 2009, 52(2):387-391.

[3] J.P.Y.Maa and J.I.Kwon: Using ADV for cohesive sediment setting velocity measurements. Estuarine. Coastal and Shelf Science, Volume 73, Issues1-2, June
2007, Pages 351-354.

[4] Hendersen, Francis M: Open Channel Flow: New York, MocMillan C0., 1966, 85-86.

[5] Munk, W.H and E.R. Anderson: Note on the theory of the thermo cline. Mar Res, 1948(7): 34-35.

[6] WAN Xinning, LI Jiufa: SHEN Huanting. Distribution and diffusion of suspended sediment in the offshore area of Changjiang estuary.Geographical Research,, 2006,25(2): 294-302.

[7] SHI Zhong, ZHU Wenwei, ZHOU Hongqiang: Settling velocity of fine suspended in the Changjiang estuary. Journal of Shanghai Jiao tong University, 2000, 34 (1):1823.

[8] Pritchard D W: Observations of Circulation in Coastal Plain Estuaries. IN: Lauff G H.Eetaries. Washington D C: AAAS Publ, 1967, 37-38. 